\title{
VARIACIÓN EN LA IMAGEN DE LA PRUDENCIA: ENTRE LA TRADICIÓN Y LA «NUEVA VISUALIDAD»
}

\author{
VARIATION ON THE IMAGE OF PRUDENCE: \\ BETWEEN TRADITION AND «NEW VISUALITY»
}

María Montesinos Castañeda Universitat de València

ABSTRACT • Although Italian influences prevail in the visual tradition of Prudence, beginning in the $15^{\text {th }}$ century a new iconographic type emerges as a result of a "new visuality" deriving from French art. This innovation has been considered "monstrous» and breaking with the preceding visual tradition. However, this new visual manifestation is a result of the continuation of philosophic theories about Prudence. What is more, Italian art offers a response to the "new visuality" with another new iconographic type of the Prudence.

KEYWORDS: Prudence; Iconography; Visual Culture; Italian Art; French Art; Early Modern Age.

RESUMEN • Aunque en la tradición visual de la Prudencia imperan las influencias italianas, a partir del siglo XV surge un nuevo tipo iconográfico fruto de la "nueva visualidad» procedente del arte francés. Dicha innovación ha sido considerada «monstruosa» y rompedora con la tradición visual precedente. Sin embargo, esta nueva manifestación visual es fruto de la continuación de las teorías filosóficas sobre la Prudencia. Además, el arte italiano ofrece una respuesta a la «nueva visualidad» con otro nuevo tipo iconográfico de la Prudencia.*

PALABRAS CLAVES: Prudencia; Iconografía; Cultura visual; Arte italiano; Arte francés; Edad Moderna.

Fecha recepción: 19-6-2019/ Fecha aceptación: 22-11-2019

* Esta investigación se ha realizado gracias a la financiación de la Universitat de València y su programa de ayudas "Atracció de Talent». 
En el siglo XV comenzamos a ver la aparición de nuevos tipos iconográficos de las Virtudes Cardinales (a excepción de la Justicia), ya que estas son portadoras de nuevos atributos que tratan de definir su esencia al tiempo que rompen totalmente con la tradición, constituyendo más que una variación del tipo iconográfico. Mâle bautizó dicha innovación visual con el término "Nueva Iconografía», ${ }^{1}$ con el fin de designar las variaciones visuales de los siglos XV y XVI que rompían con la tradición precedente. Sin embargo, para hacer referencia a esta innovación usaremos la denominación «nueva visualidad», ya que «Nueva Iconografía» emplea el término "iconografía» como contenido visual, no como una metodología de estudio (García Mahíques, 2009: 343). Según Mâle, la «nueva visualidad» apareció hacia 1470 (Mâle, 1925: 316), aunque se ha mantenido como mediados del siglo XV a partir de la discusión de diferentes manuscritos que muestran esta nueva imagen ya en 1450 (Tuve, 1963: 284). Tuve insiste en que esta tendencia visual se originó bastante antes de las suposiciones de Mâle, pues, aunque la fecha exacta no ha sido determinada, dicha autora la fija hacia 1400-1402 (Tuve, 1963: 287-288). De este modo, Tuve no solo ha cambiado la fecha de origen de la «nueva visualidad», sino que ha mostrado que el tema y propósito de esta no constituye una desviación radical del tratamiento tradicional de las Virtudes Cardinales (O’Reilly, 1988: 120). Sí es cierto que la representación naturalista de las Virtudes Cardinales y Teologales durante los siglos XIII y XIV contrasta con la imaginería alegórica que tipifica la «nueva visualidad» de cuantiosas obras del siglo XV. Esta representa las Virtudes Cardinales como doncellas vestidas a la manera contemporánea sentadas o de pie en interiores contemporáneos, con una extraordinaria colección de atributos. Dichas novedades son calificadas por Mâle como arbitrarias y bruscas (Mâle, 1925: 311-318), lo que explica la creación de nuevos atributos como respuesta frente a la carencia de una tradición precedente directa (Mâle, 1925: 311). En la primera mitad del siglo XV, diversas miniaturas de las Virtudes muestran el vacío de atributos, siendo muestra de ello la miniatura de un texto titulado San Agustín (1469) donde las Virtudes no portan ningún elemento que las identifique (Burris, 1997: 39). Según Burris, la inusual ausencia de atributos fue seguida de una modificación en las representaciones de las Virtudes a finales del mismo siglo, ya que en la segunda mitad del siglo XV aparecen representaciones significativamente diferentes a las personificaciones anteriores de las mismas (1997: 39-40). Sin embargo, las Virtudes Cardinales ya poseían atributos identificativos desde el siglo IX, lo que se fue acrecentando en los siglos posteriores, por lo que la ausencia de ellos en San Agustín es una excepción, por lo que no es seguro que la innovación visual fuera una respuesta a ello. Por lo tanto, durante el siglo XV y parte del XVI, los artistas abandonaron los atributos tradicionales de las Virtudes para desarrollar la llamada «nueva visualidad», la cual según Mâle no proviene de ninguna tradición teológica o histórica sino de la propia imaginación (Mâle, 1925: 311).

1. Sin embargo, al ordenar la visualización de las Virtudes, autores como Bonardi las han clasificado en diferentes fases. En primer lugar, se suele hacer referencia a las «Virtudes guerreras» como aquellas que luchan contra los Vicios en la psicomaquia. A continuación, al ser portadoras de divisas identificativas se las ha llamado "Virtudes emblemáticas». Por último, para referirse a esta "nueva visualidad», se las ha llamado «Virtudes simbólicas» por estar cargadas de muchos atributos (Bonardi, 2010: 57). Sin embargo, al emplear este último término parece sobreentender que anteriormente al siglo XV las Virtudes no portaran atributos -definidos como objetos simbólicos- por lo que dicha novedad no va ligada a ese "simbolismo" que se les confiere, sino a una visualización más específica de todos los aspectos y funciones que las caracterizan. De todos modos, calificar de "simbólicos» atributos es una generalización inapropiada, ya que debe diferenciarse entre "símbolo" y "recurso retórico» metáfora, alegoría, etc. -, el cual en algún caso puede estar basado en un concepto simbólico, mas no siempre (García Mahíques, 2009). 
En el Breviario de Carlos V, tan solo tres o cuatro Virtudes de las siete tienen atributos que ayudan a identificarlas, entre ellas la Justicia que presenta una balanza. Mientras tanto, los italianos fueron fieles a los tipos iconográficos que la Francia del siglo XIII había creado: como la Prudencia con una serpiente y la Fortaleza con su espada/lanza y escudo, tal y como aparecen en las portadas de las catedrales francesas. Sin embargo, las Virtudes francesas del siglo XV portan nuevos atributos en ambas manos, diferentes a los italianos. ${ }^{2}$ Según Tuve, los bizarros objetos simbólicos no son "atributos» como Mâle los llama, sino que se adaptan a las funciones de los aspectos definidos de cada Virtud (Tuve, 1963: 283). No obstante, entendemos el término "atributo" como «un recurso de la retórica visual consistente en la representación de objetos que traducen cualidades abstractas, o bien aluden a algo» (García Mahíques, 2009: 239). Por lo tanto, los objetos que sostienen las Virtudes son calificados de atributos, puesto que sigan o no la tradición, fruto de la continuidad o la variación, representan cualidades de las personificaciones a las que acompañan. Estos aspectos de cada Virtud que Tuve no considera que puedan ser denominados atributos, son las cualidades que caracterizan a cada una de ellas -lo que los filósofos han llamado partes- y están presentes tanto en los atributos que ofrecen continuidad como en la más radical variación que constituye la «nueva visualidad».

\section{LA «NUEVA VISUALIDAD» Y LA PRUDENCIA}

Hasta el siglo XIV, la Prudencia presenta diferentes tipos iconográficos en sus representaciones. Sin embargo, los atributos predominantes en la imagen de esta virtud eran los siguientes: libro, serpiente, espejo, antorcha y aspecto bifaz o trifaz. ${ }^{3}$ Si bien la serpiente proviene del ámbito francés, el resto de atributos se manifestaron principalmente en el ámbito italiano, dando lugar a interacciones entre ambas propuestas. Sin embargo, en el siglo XV surgió un nuevo tipo iconográfico de la Prudencia en el ámbito francés que rompía con toda tradición visual precedente. Concretamente, la Prudencia se representa en la «nueva visualidad» haciendo hincapié en dos de sus aspectos funcionales, la elección y las consecuencias de la imprudencia: la muerte. En la Tabla de Cebes ya encontramos expuesta dicha reflexión:

Porque la imprudencia es la Esfinge de los hombres, la cual les propone enigmas semejantes: cuál es en la vida lo bueno, cuál lo malo, cuál ni bueno ni malo. Si esto, pues, no lo entendiere alguno, muere a manos de la imprudencia, no de una vez, como el que murió comido de la Esfinge, sino que casi en todo el discurso de su vida va pereciendo, como los que van condenados a galeras para siempre (Cebes, 1947: 122).

Por estos motivos, la Prudencia comienza a acompañarse de una serie de atributos no aparecidos en su imagen hasta el momento, los cuales hacen referencia a sus características. Cristina de Pizán, en su tratado Le libre des trois vertus -escrito hacia 1405 para Margarita

2. "Alors que les Vertus françaises $d u X V^{e}$ siècle n'ont pas assez de leurs deux mains pour porter leurs jouets d'enfant, les Vertus italiennes abandonnent tout ce qui n'est pas essentiel, expriment surtout par leur attitude l'élan interieur» (Mâle, 1925: 322).

3. El libro es el primer atributo con el que se representa la Prudencia ya en el siglo IX. Habrá que esperar al siglo XII para la aparición de la serpiente, hasta finales del siglo XIII para la representación del aspecto bifaz o trifaz, así como hasta el siglo XIV para la incorporación del resto de atributos, como ya se ha estudiado (Montesinos, 2014 y 2017). 
de Borgoña-, presenta como narradora a Prudence Mondaine (libro I, capítulos XI-XIX), quien recomienda a la princesa cultivar la buena voluntad hacia los otros y manejar ella las finanzas del hogar con cuidado, encontrando así el éxito en el cielo y en la tierra. ${ }^{4}$ En el manuscrito Laud 570 de esta obra (Cristina de Pizán, 1450, Oxford, Bli, ms. Laud Misc. 570) [fig. 1] la Prudencia sostiene un ataúd sobre su cabeza, lleva un espejo, un escudo con historias de la Pasión, una criba y a sus pies reposa una bolsa de la que salen monedas de oro, creando un nuevo tipo iconográfico en el que solo reconocemos el espejo y que se explica en el texto que la acompaña. ${ }^{5}$ Según Tuve (1963: 284), el hecho de que la Prudencia a veces tenga como "escudo" la representación de emblemas de la Pasión confirma el énfasis de la victoria sobre la muerte y su remedium, el cual se encuentra bien expuesto en los textos. Además, lleva una criba con el fin de discernir entre lo verdadero y lo falso ya que la Prudencia puede ser la Sabiduría práctica que discierne entre lo bueno y lo malo, así como hace referencia a la Precaución o Circunspección (partes de dicha virtud) que se lleva a cabo cuando ellas separan a las Virtudes de los Vicios, guardando solo lo bueno (Tuve, 1963: 288). De este modo, la criba es la manifestación visual de una de las funciones de esta virtud, la cual ya exponía Artístóteles: «Corresponde a la sabiduría o prudencia el deliberar, el juzgar los bienes y los males y todas aquellas cosas que en la vida hay que desear o hay que evitar" (Arist. $V V$ 4, 1250 a 30). ${ }^{6}$ Asimismo, respecto a la elección en la Prudencia explica Fray Íñigo de Mendoza en su Vita Christi:

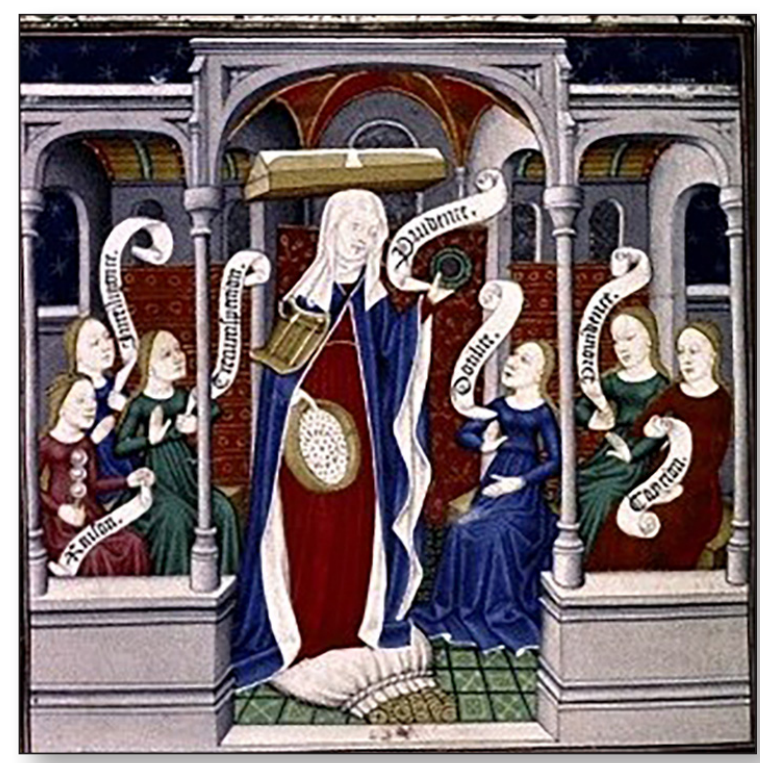

Fig. 1. Cristina de Pizán, La Prudencia y sus partes, Livre des trois vertus, 1450, Oxford, Bli, ms. Laud Misc. 570.

4. "Et en ceste maniere, par les vii susdits enseignements de Prudence tenir avec les autres susdictes vertus [...] pourra la sage dame acquerir los, gloire, renomee, grant honneur en cest monde et a la parfin paradis, qui est promis aux biens vivans" (Citado por: Burrow, 2000: 44).

5. "De bonne coutume s'amort (se mortifie) / qui pensé souvent à sa mort. / En beau miroir sa face mire / qui son estat voit et remire. / Mémoire de la Passion / targe male tentation. / Discrétion (discernement) esto u gredier (le crible) / quant du grain retrait le paillier. / Ce n'est que peine et décenance / d'amasser planté de chevance» (Citado por: Màle, 1925: 315).

6. Aristóteles define la Prudencia en más partes de su obra, como por ejemplo: Arist. EN 6, 5, 1 140a 25; Arist. EN 6, 12, 1144a 5 y Arist. EN 6, 5, 1140 b, entre otras. 
Llamo aquel entresacar / y desylar, / que con discreta sentencia / suele hazer la / prudencia / enla conçiençia / al tiempo de su mirar; / por que asy como alimpiar / y apartar / suelen la paja del grano, / asy desyle su mano / délo sano / los hilos que su labrar / condene para cortar (Mendoza, 1912: 78).

De este modo, la Prudencia con la criba parece indicar que separa el grano de la paja mientras con el espejo trata de conocerse a sí misma (Sebastián, 1988: 306). Ripa hace referencia a la criba, pero no como atributo de la Prudencia sino de la Sabiduría, aunque compartiendo el mismo significado:

«otros la representaban con una criba o cedazo, mostrándose con ello aquel efecto de la Sabiduría que consiste en distinguir y separa el grano de la paja, o también la buena simiente de la que es mala y perniciosa para las costumbres y acciones de los hombres» (Ripa, 2007: 282).

También Horapolo, en su jeroglífico "Letras», representa un cedazo como instrumento de separación del bien y el mal, como ayuda a la correcta decisión (Horapolo, 1991: 117), explicación que Juan de Horozco (1604: I, 23, 64r), Juan de Borja (1680: 348-349) y Scipion Bargagli (1574: 212) comparten empleando el mismo objeto. Por este motivo, encontramos a la Prudencia portando una criba en la sillería del coro de St. Maria in Auhausen (1516, Bayern, Landkreis Donau-Ries) [fig. 2] y en el Sepulcro de Juan II e Isabel de Portugal de Gil de Siloé (1489-1493, Burgos, Cartuja de Miraflores).

Por otro lado, la escarcela de monedas indica que la Prudencia cristiana vuelve su mirada hacia las cosas eternas, pisando los bienes de este mundo, porque piensa que en el momento de la muerte no nos acompañarán todas esas riquezas, mientras que, para luchar las fuerzas sobrenaturales contra el mundo se cubre del recuerdo de la Pasión como de un escudo (Mâle, 1925: 315). Semejante imagen encontramos en una ilustración del Fleur des histoires de Jean Mansel (BMu, Add. ms. 6797 fol. 276), donde la Prudencia tiene un espejo y un ataúd marcado con una cruz, mientras que en el ejemplar de Bruselas (s. XV-XVI, Bruselas, BR, ms. 9232, fol. 448v), de esta misma obra, la Prudencia lleva la criba y una bolsa de la que se derraman monedas. En la representación de las siete Virtudes de la Etique Aristotle (1452, Rouen, BM, ms. fr. 927. I 2, fol 17v) [fig. 3] encontramos una imagen muy similar, aunque en este caso sin la bolsa de monedas. También en el manuscrito del duque de Nemours (ca. 1477, París, BNF, franç. 9186, fol. 304) [fig. 4] la Prudencia presenta estas características. En cuanto a la bolsa de monedas, además de significar el rechazo de los bienes terrenales, hace referencia al rechazo de la Circunspección a la Avaricia (Tuve, 1963: 283).

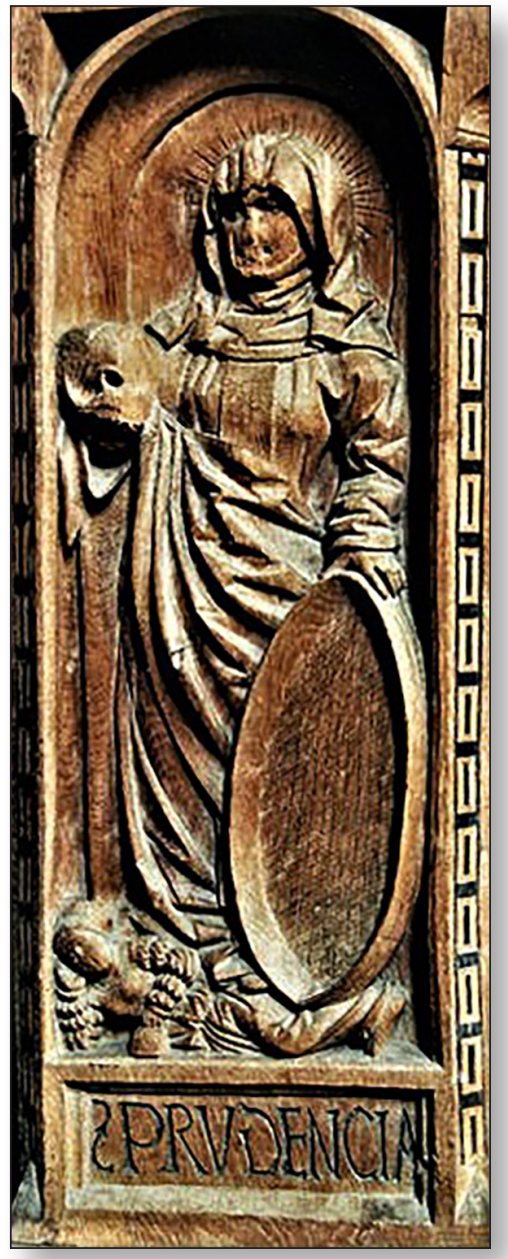

Fig. 2. Melchior Schabert, La Prudencia 1519, Bayern, Landkreis Donau-Ries, St. Maria in Auhausen, detalle de la sillería del coro. 


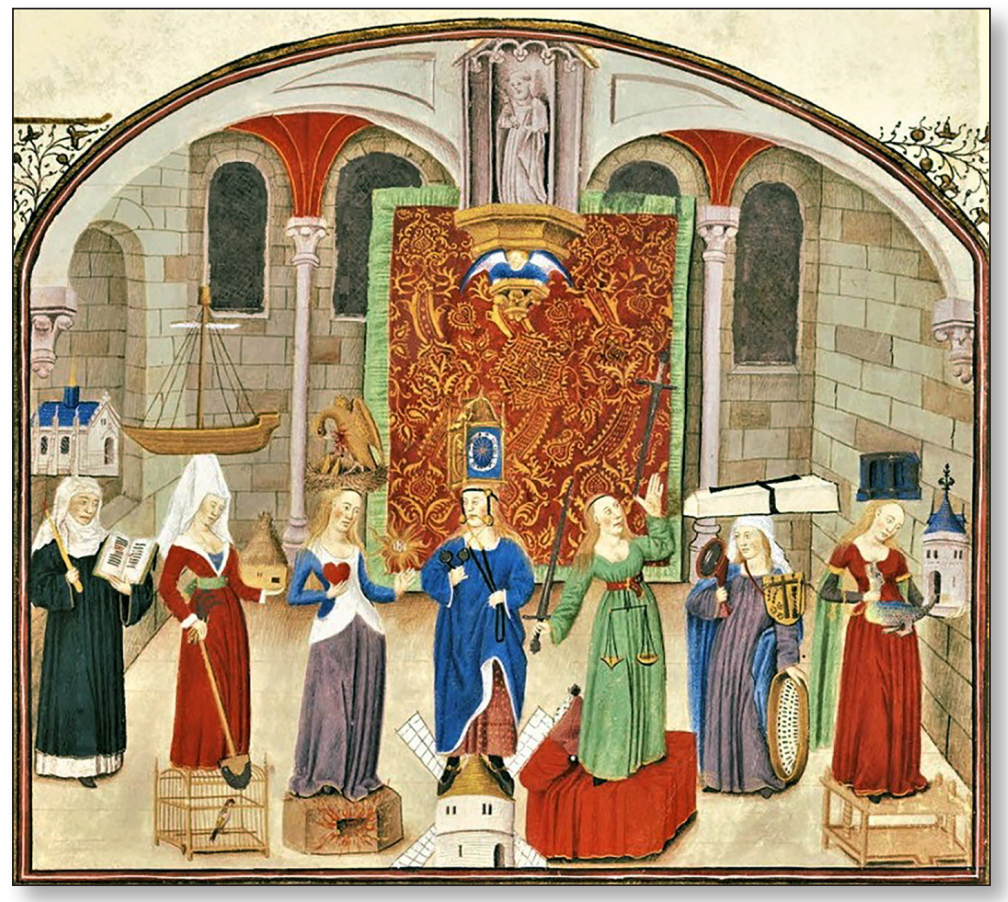

Fig. 3. Las siete Virtudes, Ethique Aristotle, 1452, Rouen, BM, ms. fr. 927. I 2, fol. 17v.

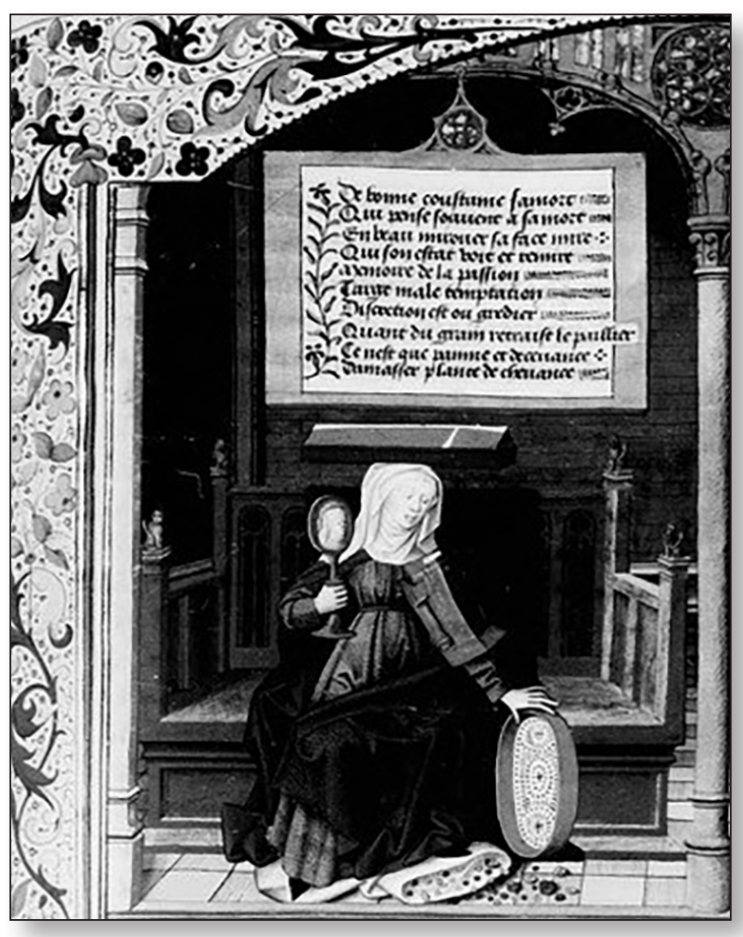

Fig. 4. La Prudencia, Manuscrito del duque de Nemours, ca. 1477, París, BNF, franç. 9186, fol. 304. 
Concretamente, el significado de la escarcela de monedas se halla en un tópico que encontramos reflejado en el pensamiento del mundo antiguo y que se refiere a la moderación y Prudencia que debe existir en la administración de la hacienda: «Corresponde a la sabiduría o prudencia (...) el emplear dignamente todos los bienes disponibles" (Arist. VV 4, 1250 a 30). El tópico en cuestión procede de Aristóteles, quien dedica en la Ética a Nicómaco unas reflexiones sobre la liberalidad, la cual considera como el medio prudente en todo lo relativo a la riqueza (Arist. EN IV, 1). Una de las odas de Horacio sentencia: «Ningún brillo tiene el dinero, ó amado Crispo Salustio, enemigo de los tesoros escondidos en la avara tierra, sino brilla con un uso moderado" (Hor. carm. 2, 2, 1). La misma idea recoge Séneca en sus Epístolas morales: «El liberal, aún para dar busca ocasión» (SEN. epist., 64) y «No guardes mezquinamente tus bienes, ni los derrames con prodigalidad» (SEN. epist., 87). Será Plutarco, no obstante, quien nos proporcione la más explícita asociación de la Prudencia con la liberalidad en su Escrito de Consolación a Apolonio: «también la Prudencia se ocupa del bien de cuatro modos: adquiriendo los bienes, guardándolos, aumentándolos o empleándolos sabiamente. Estas son las leyes de la Prudencia» (León Coloma, 1989: 226). La misma idea volvemos a encontrarla redefinida en la literatura y la visualidad del siglo XVI, cuando Castiglione reproduce el argumento aristotélico a propósito de la liberalidad y concluye advirtiendo: "Así que en estas cosas --las relativas a la liberalidad--, como en todas las otras cosas, es necesario saber y gobernarse con la Prudencia» (Castiglione, 1994: 408). El tópico se consagra en la Iconología de Ripa, que nos describe a la «Parsimonia o Prudencia en el gasto" [fig. 184] provista de una bolsa cerrada y repleta de dinero, con un letrero que reza: «Guarda para mejor» (Ripa, 2007: 181). Ripa explica más sobre la relación entre ambos conceptos: «La Parsimonia o Prudencia en el gastar es uno de los principales componentes que conforman la liberalidad, consistiendo esta virtud en evitar aquellos desembolsos no conformes a la razón que rebasan y desbordan el justo medio" (Ripa, 2007: 181). La Parsimonia posee tres de aquellas cuatro partes de la Prudencia que se refieren a los bienes de fortuna, lo que justifica haciendo referencia a Horacio de la siguiente manera: «Pues, en relación a un bien, la Prudencia se conduce de cuatro maneras, puesto que consigue bienes, los guarda, los aumenta o los usa con Prudencia; estos son los cánones de la Prudencia y de las demás virtudes» (Hor. sat. 3, 2). Además, respecto a la bolsa de dinero, Ripa explica: «La bolsa con el letrero que dice: In melius servat, nos muestra claramente que hay mayor honor y se precisa mayor inteligencia para lograr conservar lo que se tiene, que no para adquirir lo que nos falta, como muestra Claudiano, lib.II, In Stilicon: 'plus est servasse repertum. Quam quaesisse decus novum'» (Ripa, 2007: 182). Este atributo aparece en más representaciones de la Prudencia, como la del Sepulcro de don Álvaro de Luna (Pablo Ortiz, s. XV, Catedral de Toledo, Capilla de Santiago), aunque en este caso la escarcela no figura abierta y arrojada en el suelo, como en las miniaturas francesas, sino que por el contrario permanece cerrada y bien custodiada por la doncella (León Coloma, 1989: 68). Por lo tanto, la representación de la Prudencia con una bolsa de monedas es la transcripción visual de un tópico perfectamente definido en la Antigüedad que enfatizaba una nueva dimensión de la Prudencia: la correcta distribución de la hacienda (León Coloma, 1989: 68). La criba, el saco de monedas y el ataúd también aparecen como atributos de dicha virtud en una miniatura del Le séjour de deuil pour le trespas de Messire Philippes de Commines (1512, La Haya, KB, ms. 76 E 13) [fig. 5] o en Las siete Virtudes de Bruegel (1560, Ámsterdam, RijM, RP-P-OB-7377) [fig. 6], entre otras. 


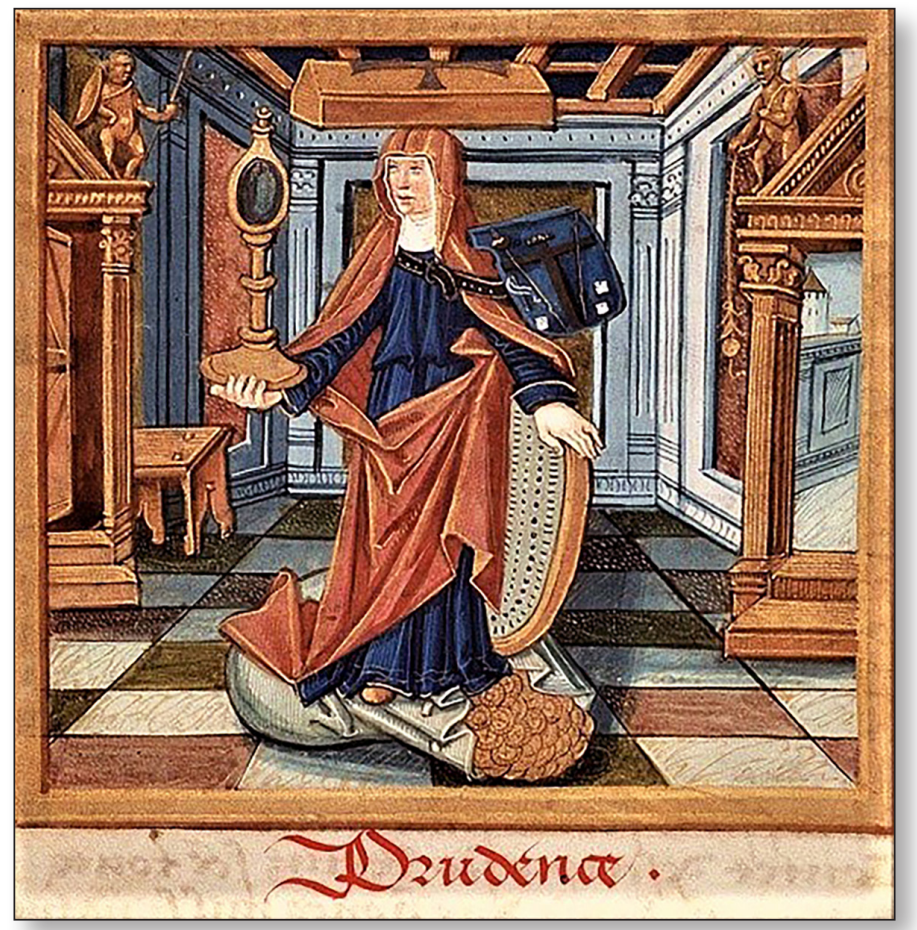

Fig. 5. La Prudencia, Le séjour de deuil, 1512, La Haya, KB, ms. 76 E 13, fol. 5 r.

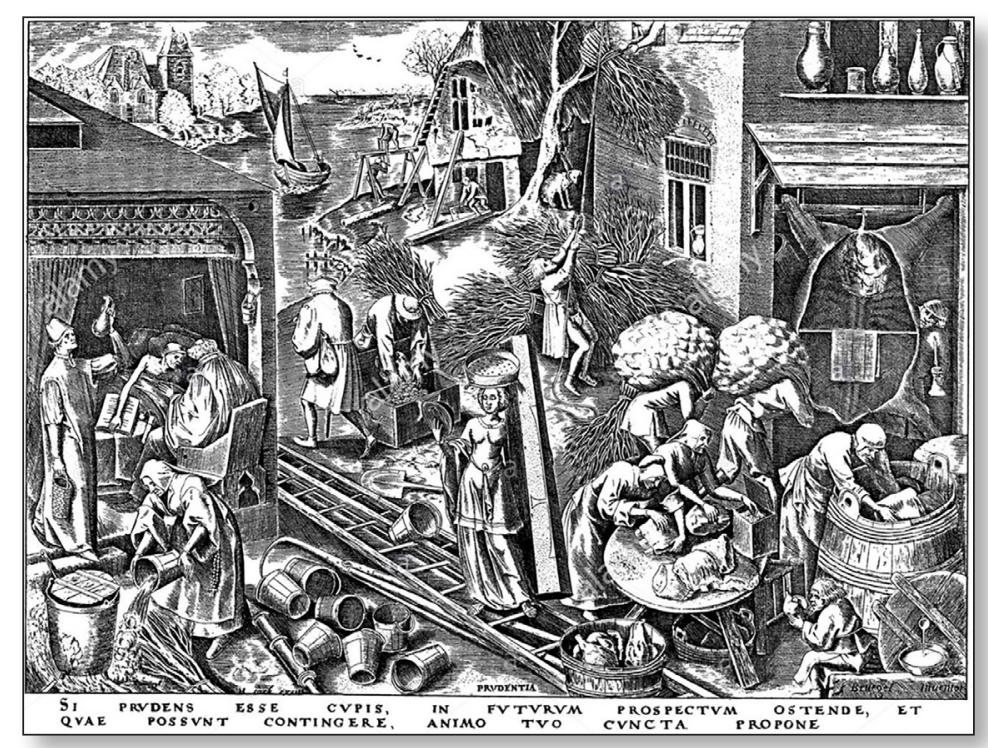

Fig. 6. Pieter Bruegel, La Prudencia, Las siete Virtudes, 1560, Ámsterdam, RijM, RP-P-OB-7377. 


\section{LAS DAMAS DE LA PRUDENCIA EN SU VISUALIDAD}

El Bodley ms. Laud 570 (1450, Oxford, Bli) [fig. 1] contiene una copia del Epître d'Othéa -basado en Chapelet des Vertus- (Rouse, 2008: 196) de Cristina de Pizán (1364-ca. 1430), donde encontramos a la Prudencia ilustrada conforme a la "nueva visualidad». Según O'Reilly (1988: 122), la ilustración a primera vista parece inapropiada, pero Tuve (1963: 264-303) ha mostrado no solo que Cristina de Pizán demuestra con ella su familiaridad con la tradición clásica, sino que concretamente este manuscrito de su Epître, contiene un tratado francés, Livre des quatre Vertus Cardinaulx (fols. 1-23v), una traducción parcial posiblemente realizada por Cristina, del tratado de John of Wales (s. XIII-1285) Breviloquium de virtutibus (O'Reilly, 1988: 122). Este tratado muestra a la Prudencia, no solo con los nuevos atributos sino también acompañada de unas damas que se identifican como las personificaciones de sus partes. Cicerón concibió las partes de las Virtudes como formas de manifestación de las cuatro Cardinales, lo que Macrobio siguió y que se visualiza a través de la «nueva visualidad». Concretamente, el primero en distinguir las subdivisiones que componen la Prudencia fue Aristóteles: Memoria, Experiencia, Perspicacia y Deliberación (Arist. $V V 4,1250$ a 30-40). Cicerón (Cic. inv. 2, 53, 160) se basó en la propuesta aristotélica, mientras que Macrobio las amplió: «La prudencia comprende la razón, el intelecto, la cautela, la previsión, la facilidad de aprender, y la precaución» (MACR. somn. 1, 8, 7). Los autores medievales siguieron a los pensadores clásicos, ${ }^{7}$ de entre los que podemos destacar la aportación de santo Tomás de Aquino, ${ }^{8}$ quien consideró hasta ocho partes: «De estas ocho, cinco pertenecen a la prudencia como cognoscitiva: la memoria, habilidad en el raciocinio, inteligencia, docilidad y sagacidad; y tres a la prudencia como preceptiva, a saber: la previsión o providencia, la circunspección y la precaución» (S.Th. [41055] II ${ }^{a}$-IIae q. 48 co.). En los siglos siguientes las partes de la Prudencia continuaron variando dependiendo del pensador que las citara, sin coincidir en número ni en nombre. Más tarde, en el capítulo XVIII -de la Prudencia- de Flor de Virtudes (1313-1323), fray Tommaso, basándose en Cicerón, citó como partes de la Prudencia tan solo tres (Memoria, Inteligencia y Providencia), aunque hace referencia a cuatro más (Discernimiento, Razón, Consejo y Diligencia). ${ }^{9}$ También siguió a Cicerón Michael de Praga, ya que en su De regimine principum (1387) tan solo cita como partes de la Prudencia tres: Memoria, Inteligencia y Providencia. Francisco de Imperial, en El dezir de las syete virtudes (ca. 1407) presentó la imagen literaria de la Prudencia aludiendo así mismo a sus partes:

7. Alain de Lille mantiene la Razón, la Providencia y la Precaución que Macrobio había citado, añadiendo la Circunspección y la Docilidad a las partes de la Prudencia. Sin embargo, en su Tratado de las Virtudes destaca que normalmente los teólogos enumeran tan solo tres: la Providencia, la Circunspección y la Precaución. Por su lado, Hugo de san Víctor, tomando como referencia las reflexiones de los diferentes pensadores, hizo brotar de la rama de la Prudencia que sostiene el árbol de las Virtudes, ocho hojas correspondientes a las partes de esta virtud: Ratio, Consilium, Diligentia, Modestia, Memoria, Providentia, Timor Dei, Tolerantia. Por lo contrario, Bono Giamboni, en Il libro de' vizî e delle virtudi (s. XIII), redujo las partes a cinco, sin llegar a coincidir del todo con ningún autor precedente, sino combinando las distintas propuestas: "Buona memoria, Buono conoscimento, Buono provedimento, Buono esaminamento, Buona elezione» (Giamboni, 1968: 5).

8. Santo Tomás distinguió entre partes integrales, esenciales y potenciales. Las que enumeramos son las integrales.

9. «Según Tulio tiene tres virtudes: la primera es haver recuerdo e memoria de las cosas pasadas; la segunda es inteligencia de discernir las cosas que ha de fazer, conviene saber, el bien del mal e la verdad de la falsía, e ordenar sus cosas por forma de razón; la tercera es providencia, conviene saber proveer ante del tiempo a los negocios. $/$ E estas tres virtudes se informan por dos otras maneras, que son consejo e diligencia» (Mateo Palacios, 2013: 67).

IMAGO, NÚM. II, 2019, 153-169 
Mira Prudençia commo faz loçanas / sus anbas fazes mirando el espejo, / e de una en una mira sus hermanas, /e cura dellas quando non son sanas; / Providençia, Conprehender, Enseñamiento, / Cautela, Soliçidat, Acatamiento; / éstas sson fijas, en obras non son vanas (Imperial, 1977: 112).

Igualmente, Dom Duarte, basándose en Aristóteles (Carvalho, 2007: 940), incluye como aquello que es necesario para alcanzar la Prudencia: "poseer capacidad para recordar, es decir Memoria; ser avisado, previendo lo que ha de acontecer, Providencia; contar con buenos consejeros, Consejo; y la sabiduría" (Citador por: Carvalho, 2007: 938). Francisco de Guzmán, quien en sus Triumphos morales sí explicó claramente qué partes considera que forman a la Prudencia:

De muchas grandes partes fue prudencia / compuesta, por las quales es guiada, / y aquella que le da mayor potencia / memoria por vosotros es llamada. / Y en ella toma fuerças experiencia / que poco menos debe ser preciada, / industria, buen consejo que diremos / y mas si mas lugar después tenemos (Guzmán, 1565: 70r).

Aunque los diferentes autores no coinciden en la denominación y el número de partes, todas ellas son funciones que dicha virtud ha de desempeñar. Estas reflexiones teóricas tuvieron correspondencias visuales en la imagen de la Prudencia, siendo sus atributos y características visuales manifestaciones de las partes que conforman a esta virtud. Estas partes, son esas damas que acompañan a la Prudencia en el Laud 570 (1450, Oxford, Bli) [fig. 1], identificadas por sus filacterias como: Razón, Inteligencia, Circunspección, Docilidad, Providencia y Precaución. Semejante imagen encontramos un siglo antes en una miniatura de Nicole Oresme (ca. 1323-1382, s. XIV, Rouen, BM, ms. 927, fol. 93v) [fig. 7], en la que la Prudencia se rodea de sus damas: Providencia, Circunspección, Precaución y Docilidad. Por lo tanto, dicha novedad no rompía con la tradición del todo, aunque sí con la visual, no con la teórica. Consecuentemente, leer la «nueva visualidad» a la luz de la tradición clásica facilita su compren-

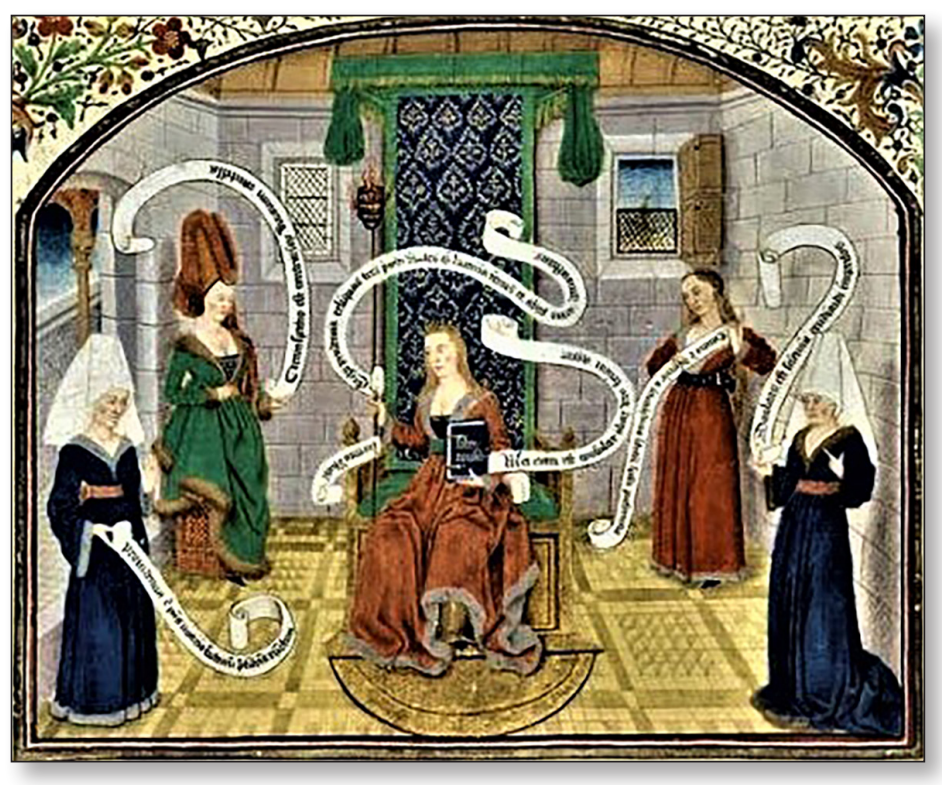

Fig. 7. La Prudencia, Ethique Aristotle, s. XIV, Rouen, BM, ms. 927, fol. 93v.

162 sión, siendo esta un método diferente de mostrar la naturaleza y relaciones de las Virtudes Cardinales y sus partes. También el Fleur des histoires (ca. 1454-1467, Bruselas, BR, ms. 9232, fol. 448v) de Jean de Mansel se caracteriza por la «nueva visualidad", al igual que Le séjour de deuil (1512, La Haya, KB, ms. 76 E 13, fol. 5r ) [fig. 5] aunque la naturaleza, función y aspectos de la Prudencia están indicados solo por atributos, no por doncellas como personificaciones de sus partes. En primer lugar, el espejo representa la Circunspección y Docilidad, por ser

IMAGO, NÚM. I I, 2019, I53-169 
objeto de reflexión, así como por su facilidad de reflejar cualquier imagen que se sitúa frente a él. Aunque el espejo existía desde la Antigüedad, en el siglo XIII se inventó el espejo de vidrio y cristal de roca, lo que puede que explicara la aparición de este atributo en la imagen de la Prudencia en el siglo XIV y su continuación dentro de la «nueva visualidad" por la novedad tecnológica que suponía (Melchior-Bonnet, 1996). No obstante, la presencia del espejo denota el intercambio visual entre territorios, ya que este atributo apareció en la imagen de la Prudencia en el ámbito italiano y se traslada al ámbito francés de la "nueva visualidad». Respecto a la criba, como ya hemos expuesto, hace referencia a la Elección y Deliberación, mientras que la bolsa de monedas es la manifestación de la Circunspección y Buena Medida. En cuanto al ataúd, representa la Precaución o Cautela que es necesaria para no ser imprudente y tener que lamentar las peores consecuencias, manifestadas en el ámbito italiano mediante la calavera, como veremos a continuación.

\section{MIGRACIONES VISUALES}

Aunque la «nueva visualidad» es propia del ámbito francés, ya que no encontramos muestra de ella en obras italianas de los siglos XV y XVI, sí existe cierto impacto visual a nivel retórico en la visualidad italiana. La presencia del ataúd en la imagen francesa de esta virtud se tradujo en la visualidad italiana con la calavera como emblema de las consecuencias que conlleva la imprudencia, así como referencia al presente (Vives-Ferrándiz, 2011: 89). Como ya explicaban algunos de los pensadores presentados hasta el momento, la principal función de la Prudencia es la elección, para la cual ha de tener en cuenta su pasado, su presente y su futuro, pues cada hecho conlleva un fin. A partir de estas premisas, en los siglos XV y XVI surgen diferentes atributos alusivos a la elección y el fin, concretamente la muerte. Según Vives-Ferrándiz: «Los ojos de la Prudencia miran hacia el presente y el pasado para descubrir que el ser humano es perecedero, mortal, en definitiva, es una calavera" (2011: 71). ${ }^{10} \mathrm{La}$ calavera, aunque se trata de un atributo poco frecuente en la virtud, ${ }^{11}$ encontramos referencias literarias y visuales de su representación en relación a la imagen de la Prudencia. Ripa, en su segunda propuesta de imagen de Prudencia introduce este atributo [fig. 8], cuyo significado explica de la siguiente manera:

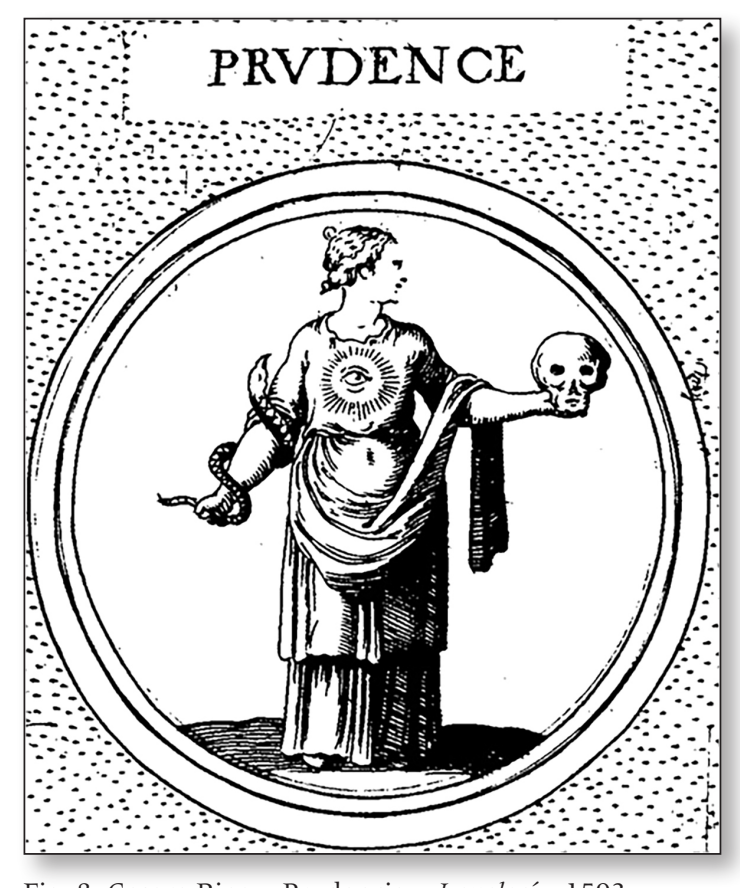

Fig. 8. Cesare Ripa, «Prudencia», Iconología, 1593.

10. Dicha relación del espejo con el reflejo de la muerte es claramente visualizada por Bonomi en el emblema XI "Huic redas" el que un esqueleto lleva colgado un espejo, queriendo significar con ello que el espejo refleja la única verdad existente, la muerte (Bonomi, 1661: 82-87).

11. Ni Mâle, ni Marle, ni Tervarent, entre otros, recogen este atributo de la Prudencia.

IMAGO, NÚM. II, 2019, I53-169 
Mujer que coge con la siniestra una cabeza de muerto, mientras sujeta una serpiente con la diestra. La cabeza de muerto nos recuerda que para adquirir el uso de la Prudencia será también de la mayor importancia atender al fin y resultado de cada cosa, siendo dicha Prudencia, en su mayor parte, efecto directo de la Filosofía. Esta a su vez, según los mejores Filósofos, es una continua meditación sobre la muerte, siendo así que el pensar en nuestras miserias es el camino real y verdadero para alcanzar la mentada Filosofía (Ripa, 2007: 237).

Según León Coloma, su origen debe ser seguramente italiano, ya que considera que fue introducido en la Península Ibérica, primero por Vasco de la Zarza (fl. 1524) y, más tarde, por Domenico Fancelli (1469-1519). Zarza hizo uso de la calavera como atributo de la Prudencia en el Sepulcro del obispo Alonso Tostado de Madrigal (Vasco de la Zarza, Catedral de Ávila) [fig. 9] y en el del obispo Carrillo de Albornoz (ca. 1515, Catedral de Toledo) [fig. 10]. No obstante, a Fancelli se debe la considerable difusión de dicho atributo en Castilla, a partir de la fascinación que el Sepulcro del príncipe don Juan (Domenico Fancelli, 1512-1513, Iglesia de Sto. Tomás de Ávila) [fig. 11] suscitó, siendo obra italiana e innovadora en muchos aspectos para la tradición escultórica funeraria vigente en territorio peninsular (León Coloma, 1989: 68). Aquí, la Prudencia se representa semidesnuda, teniendo una serpiente enroscada en un brazo apoyando la otra mano sobre una calavera que sostiene sobre una pierna, como en los sepulcros de Zarza. La calavera se explica como el memento mori por excelencia, que constituye, en manos de la Prudencia, una advertencia sobre la caducidad de la vida, y un llamamiento al ejercicio de esta virtud, lo que justificaría el éxito de este atributo de la Prudencia cuando esta aparece en contextos funerarios. ${ }^{12}$ Se trata, pues, de la conjunción de la idea de vanitas, por una parte, y de la visualidad de la muerte por otra (León Coloma, 1989: 70). Esta virtud caracteriza al desengañado ante la muerte siendo consciente de los peligros de sus decisiones y los actos que pueden llevarle a ella, así como define el momento presente a modo de una calavera, teniendo en cuenta la muerte en todo momento (León Coloma, 1989: 89). Cabe destacar, que, para Miranda y Paz, la calavera es el espejo que nos devuelve la imagen y condición de lo que somos, haciéndonos contemplar el devenir (Barbier, 1898: 213): «avia (sic.) de tener el hombre este espejo, que le representase quien es en lo natural, y moral, desmenuzando las calidades de su ser. (...) Nada fuiste, nada eres, y en nada te resuelves, aunque las apariencias de que eres algo te engañan» (Miranda, 1663: 17r). De este modo, el espejo devuelve la verdad sobre el verdadero rostro del espectador (Citado por: Vives-Ferrándiz, 201 1: 105), haciéndole reflexionar sobre sus actos, los cuales deben ser prudentes para evitar su pronta muerte. Por lo tanto, los casos en los que la Prudencia solo presenta una cara, pero aparece mirándose a un espejo y pisando una calavera podrían ser equivalentes a la representación trifaz, ya que encontramos igualmente las tres caras, siendo la calavera la del futuro, como vemos en la fachada de la Basílica de Begoña (1503, Bilbao) [fig. 12] o en Las siete Virtudes (1517-1525) de Bernaert van Orley y Pieter van Aelst. Cabe añadir que, aunque no muy comúnmente, la calavera se mantuvo como atributo de la Prudencia en los siglos sucesivos, como Gaucher recoge en su Iconologie par figures (1791) [fig. 13], explicando al respecto:

On peut la représenter tenant une tête de mort, parce que la Prudence chrétienne nous engage à méditer sur le momento terrible qui doit décider de notre malheur ou de notre félicité éternelle; ce qu'indique la maxime, consacrée par la religión, qu'on voit écrite autor du miroir que tient la Prudence chrétienne: memento quia pulvis es (Gaucher, 1791: 45).

12. También en el Sepulcro de los Marqueses de Poza (Iglesia del convento de san Pablo) aparece la calavera en manos de dicha virtud. 


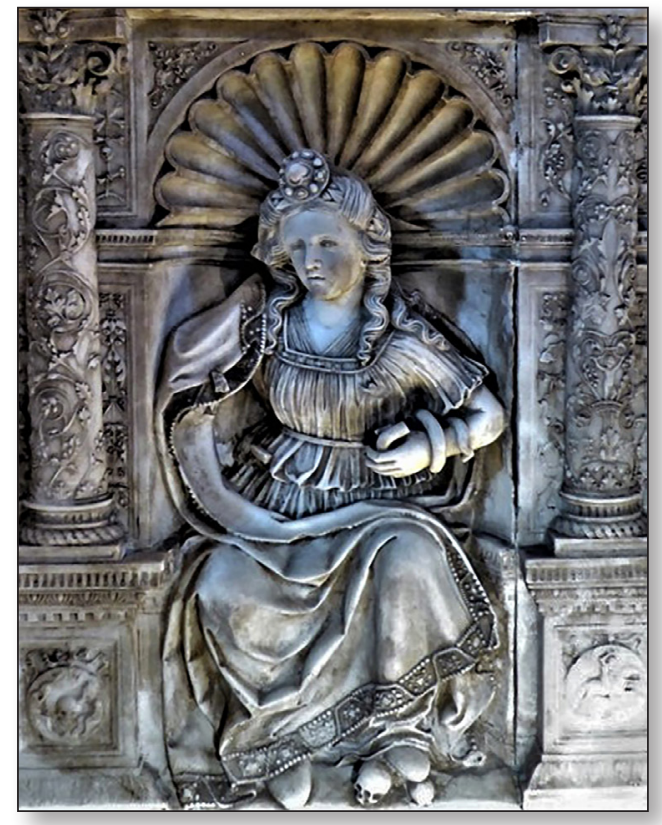

Fig. 9. Vasco de la Zarza, La Prudencia, Sepulcro del obispo Alonso Tostado de Madrigal, Catedral de Ávila.

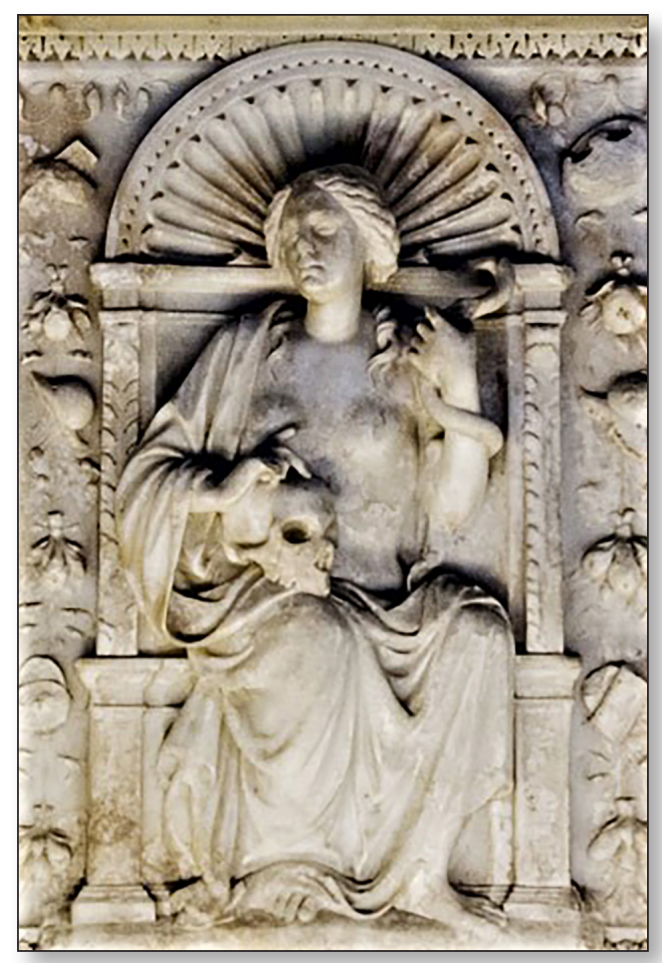

Fig. 11. Domenico Fancelli, La Prudencia, Sepulcro del príncipe don Juan, 1512-1513, Ávila, Iglesia de Santo Tomás.

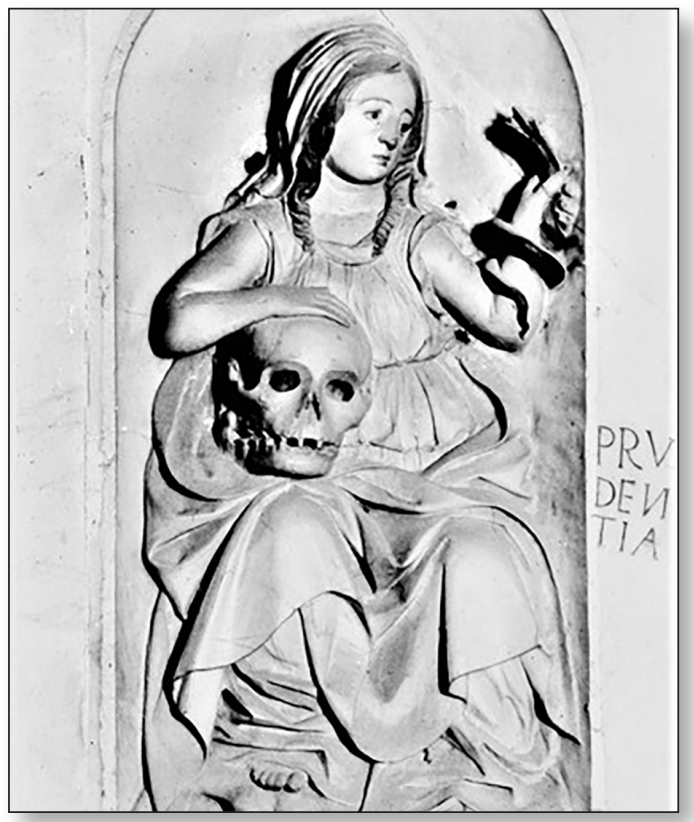

Fig. 10. Vasco de la Zarza, La Prudencia, Sepulcro de Alonso Carrillo de Albornoz, ca. 1515, Catedral de Toledo.

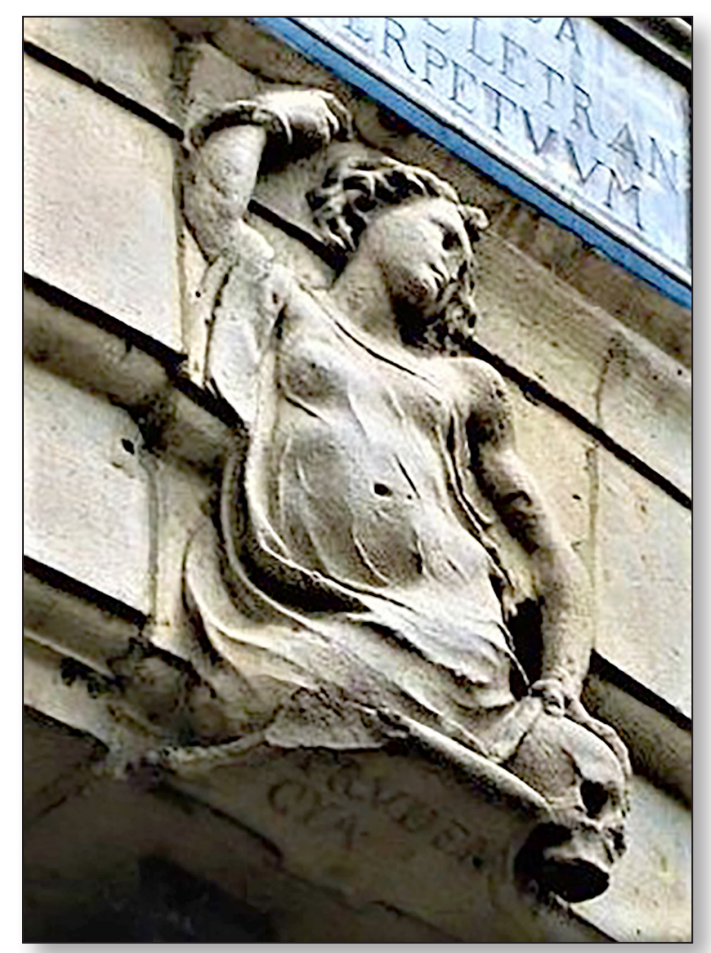

Fig. 12. La Prudencia, 1503, Bilbao, Basílica de Begoña, fachada.

IMAGO, NÚM. II, 2019, 153-169 


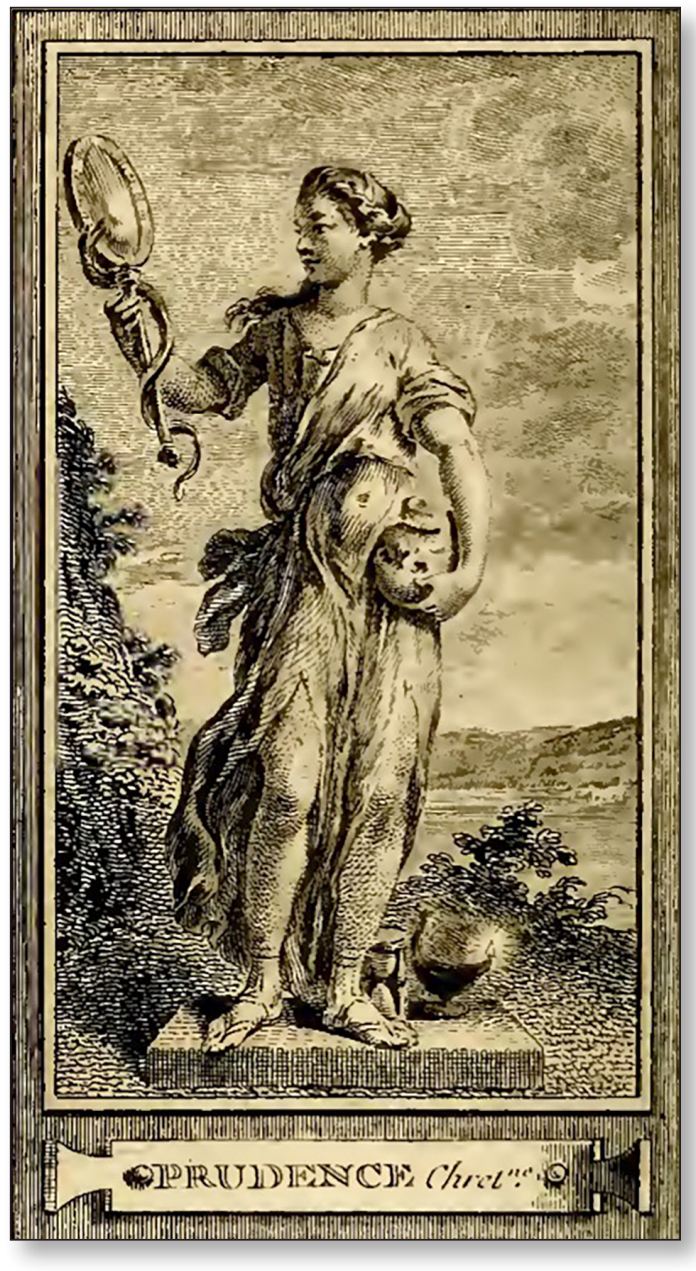

Fig. 13. C.E. Gaucher, H.F. Gravelot y C.N. Cohin, «Prudence chrétienne», Iconologie par figures..., 1791, vol. 4, p. 45.

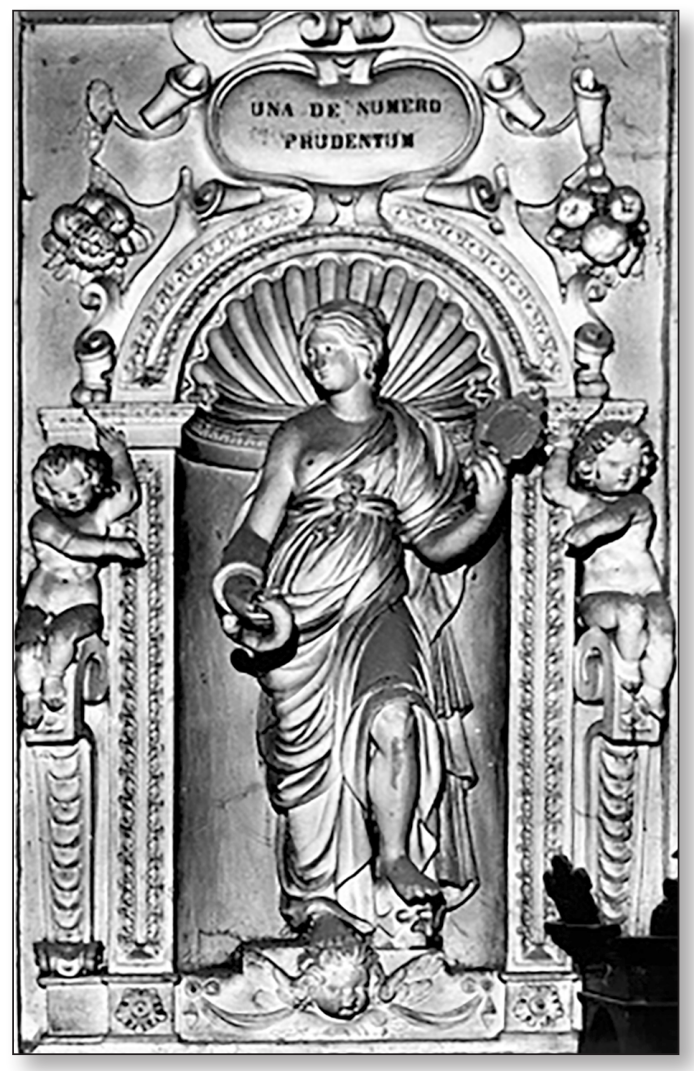

Fig. 14. Giuseppe Amisani, Prudenza, s. XVII.

Por lo tanto, la calavera continuó siendo la manifestación de las horribles consecuencias que puede tener obrar imprudentemente. Sin embargo, no es la única muestra de la Prudencia acompañada de la calavera, como bien muestra la Prudentia de

Giuseppe Amisani (s. XVII) [fig. 14], la de Hendrik van Limborch (1691-1759, Ámsterdam, RijM, RP-P-1878-A-1238) [fig. 15] o la Allegoria della Prudenza de Creti Donato (ca.17101720, Bolonia, Collezioni Comunali d'Arte) [fig. 16]. Cabe añadir que, aunque el tipo iconográfico de la Prudencia con serpiente y calavera no corresponde a la "nueva visualidad", sí es cierto que dicha concepción de la muerte deriva del tipo iconográfico que esta propuso. La presencia del ataúd surgida en el siglo XV en el contexto de la "nueva visualidad», como alusión a las consecuencias que puede conllevar a la Imprudencia, se tradujo en el ámbito italiano -aunque exportado también a otros territorios- con la presencia de la calavera. Todo ello nos recuerda a la Prudencia cristiana que concibió Gravelot [fig. 13], la cual también se acompaña del reloj de arena, la serpiente, el espejo y la calavera, como signo de las consecuencias que puede tener obrar con imprudencia. Concretamente, Gravelot explica que "L'orloge de sable désigne l'incertitude où nous sommes de notre heure dernière» (1791: 45), de modo que indica el paso del tiempo del mismo modo que la calavera, aludiendo a cómo la imprudencia puede llevar a la muerte. 


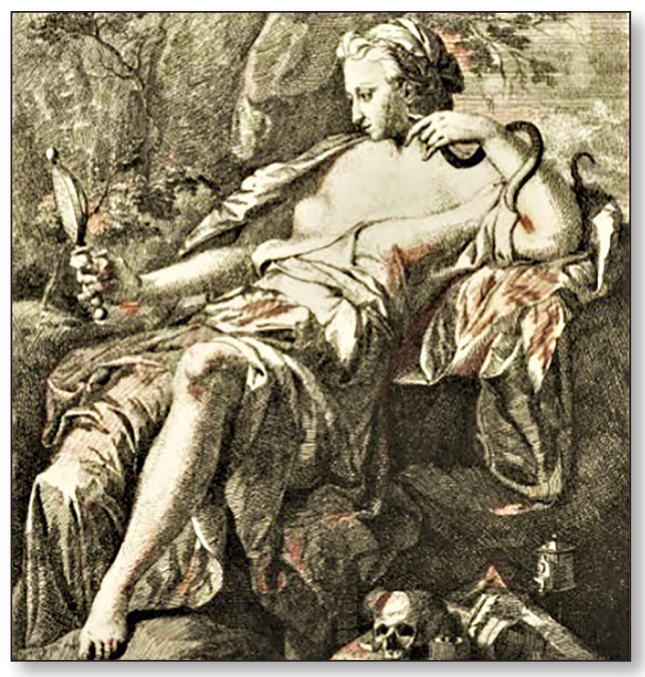

Fig. 15. Prudentia, Hendrik van Limborch, 16911759, Ámsterdam, RijM, RP-P-1878-A-1238.

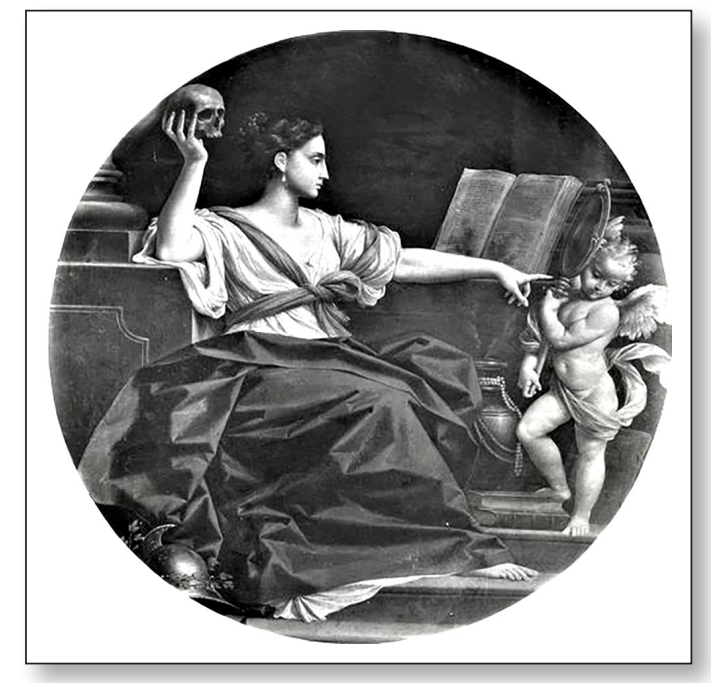

Fig. 16. Allegoria della Prudenza, Creti Donato, ca. 17101720, Bolonia, Collezioni Comunali d'Arte.

Aunque la calavera ofreció una mínima continuidad, no fue el caso de la imagen de la Prudencia en la «nueva visualidad». El espejo sí continuó como atributo de esta virtud, pero cabe recordar que su presencia no supuso una novedad ya que era propio de la tradición visual de la Prudencia. La bolsa de monedas, la criba, el ataúd y el escudo con los emblemas de la pasión no continuaron en la imagen de la Prudencia más allá del siglo XVI, periodo en el que la tradición y la «nueva visualidad» comenzaron a combinarse. En cuanto a la representación de las partes de la Prudencia como sus damas, ofrece una continuidad muy escasa posteriormente a este periodo, por lo que sus funciones quedan manifestadas ya a través de sus atributos. Tras dicha interacción fue la visualidad italiana la que predominó, haciendo desaparecer el tipo iconográfico de la Prudencia en la «nueva visualidad». Gombrich expone claramente las razones por las que la «nueva visualidad» pasó rápidamente de moda:

Paradójicamente, fue esta misma modernidad la responsable de que la "nueva iconografía» pasara de moda tan rápidamente con la llegada del Renacimiento pleno. Los humanistas recordaron el parentesco entre las personificaciones y los dioses antiguos, e igual que se devolvió a los olímpicos su forma y belleza pretéritas, también la imagen alegórica había de aparecer al modo clásico. Por mucho que admirara el siglo XVI lo extraño y enigmático, monstruos como los realizados por Leonardo difícilmente hubieran resultado aceptables, y menos aún hubiera sido posible equipar las personificaciones con divisas de nueva creación, pues había que conservar el aspecto de una imagen all'antica: tanto la forma como el simbolismo de la personificación tenían que llevar el marchamo de una autoridad antigua (Gombrich, 2001: 139).

Bonardi ha calificado esta decadencia de la "nueva visualidad» como consecuencia de que "L'influence italienne renouvelle l'iconographie des vertus en France et en Europe» (2010: 58), como si la preeminencia de la visualidad italiana se basara principalmente en la continuación de la visualización de las Virtudes. Sí es cierto que a partir de la Edad Moderna la variación de los tipos iconográfico aumenta, enriqueciéndose de más atributos, pero no todos ellos provienen del ámbito italiano ni consituyen una innovación. Por lo tanto, la «nueva

IMAGO, NÚM. I I, 2019, I53-169 
visualidad» marcó una etapa de variación en la imagen de la Prudencia y las Virtudes -exceptuando la Justicia- que se extinguiría rápidamente, dejando tan solo algún resquicio en la literatura emblemática, la cual recogió alguno de estos enigmáticos atributos, aunque de manera excepcional y poco frecuente.

\section{BIBLIOGRAFÍA Y FUENTES}

ARistóteles [1973]. Obras, ed. de F.P. Samaranch, Aguilar, Madrid.

BARbIER, X. [1898]. Traité d'iconographie chrétienne, Societé de libraire ecclésiastique et religeuse, París.

Bargagli, S. [1574]. Dell'imprese, Venecia.

BoNARDI, M. [2010]. Les vertus dans la France baroque: représentations iconographiques et littéraires, Honoré Champion, París.

Bonomi, G.F. [1661]. Chiron Achillis sive Navarchus Humanae Vitae, H. H. de Duccijs, Bononiae. BORJA, J. de [1680]. Empresas morales, Bruselas.

BurRis, S. [1997]. Pieter Bruegel the Elder's apocalyptic «Fortitude», University of North Texas, Texas.

Burrow, I.P. [2000]. Medieval Futures: attitudes to the future in the Middle Ages, Boydell Press, Woodbridge, UK.

Carvalho, A.L. [2007]. «Rey y 'Totalidad Nacional' en la obra de Don Duarte: en torno a los conceptos de prudencia y consejo", Hispania: Revista española de historia, 67, 227, pp. 929-944.

Castiglione, B. [1994]. El cortesano, ed. de M. Pozzi, Cátedra, Madrid.

Cebes [1947]. La Tabla de Cebes, Espasa-Calpe, Buenos Aires.

Cicerón, M.T. [1997]. La invención retórica, ed. de S. de Núñez, Gredos, Madrid.

García Mahíques, R. [2009]. Iconografía e Iconología, Madrid, Encuentro.

Giamboni, B. [1968]. Il libro de' vizî e delle virtudi e Il trattato di virtú e di vizî, ed. de C. Segre, G. Einaudi, Turín.

Gombrich, E. [2001]. Imágenes simbólicas, Debate, Madrid.

Gaucher, C.E., Gravelot, H.F. y Cochin, C.N. [1791]. Iconologie par figures, Lattré Graveur, París, vol. 4.

Guzmán, F. de [1565]. Triumphos morales, Casa de Andrés, Alcalá de Henares.

Horapolo [1991]. Hyerogliphica, ed. de J.M. González de Zárate, Akal, Madrid.

Horozco, J. de [1604]. Emblemas morales, Alonso Rodríguez, Zaragoza.

IMPERIAL, F. de [1977]. El dezir a las syete virtudes y otros poemas, ed. de Colbert I., Espasa-Calpe, Madrid.

León Coloma, M.A. [1989]. «Iconografía de la prudencia en España durante los siglos XV y XVI», Cuadernos de arte de la Universidad de Granada, 20, pp. 65-78.

Macrobio, A.T. [2006]. Comentario al «Sueño de Escipión» de Cicerón, ed. de F. Navarro Antolín, Gredos, Madrid.

MÂLE, E. [1925]. L'art religieux de la fin du moyen age en France: étude sur l'iconographie du moyen age et sur ses sources d'inspiration, Armand Colin, París.

Mateo Palacios, A. (ed.) [2013]. Flor de Virtudes, Prensas de la Universidad de Zaragoza, Zaragoza. 
Mendoza, F.I. de [1912]. «Vita Christi techo por coplas por frey Yñigo de Mendoca a petiçion de la muy virtuosa señora doña Juana de Cartagena». En: Foulché-Delbosc, R., Cancionero castellano del siglo $X V$, Bailly Bailliere, Madrid.

Melchior-Bonnet, S. [1996]. Historia del espejo, Herder, Barcelona.

Miranda y Paz, F. [1663]. El desengañado: philosophia moral, Francisco Caluo, Toledo.

Montesinos CastaÑeda, M. [2014]. "Los fundamentos de la visualidad de la Prudencia», Imago: revista de emblemática y cultura visual, Universitat de València, València, 6, pp. 97-114.

Montesinos Castañeda, M. [2017]. "El tiempo en la visualidad de la Prudencia», en B. Ballester Morell, A. Bernat Vistarini y J.J. Cull (eds.), Encrucijada de la palabra y la imagen simbólicas, José J. de Olañeta, Palma de Mallorca, pp. 505-516.

O'REILLY, J. [1988]. Studies in the iconography of the virtues and vices in the Middle Ages, Garland Pub., Nueva York.

RIPA, C. [2007]. Iconología, ed. de M.A. Allo, R.M. Mariño, F. García, et al., Akal, Madrid, vol. 2 .

Rouse, M. [2008]. «Prudence, Mother of Virtues: The Chapelet des vertus and Christine de Pizan», Viator, 2008, 1, 39, pp. 185-228.

Sebastián, S. [1988]. Iconografía medieval, Etor, Donostia.

Tomás de Aquino, S. [1955-1960]. Suma Teológica, ed. de S. Ramírez y T. Urdanoz, Editorial Católica, Madrid, vol. 8.

Tuve, R. [1963]. "Notes on the virtues and vices 1: two fifteenth-century lines of dependence on thirteenth and twelfth centuries», Journal of the Warburg and Courtauld Institutes, 26, pp. 264-303.

VIVes-FerRándiz, L. [2011]. Vanitas: retórica visual de la mirada, Encuentro, Madrid. 
